\title{
Free Serum Cortisol during the Postoperative Acute Phase Response Determined by Equilibrium Dialysis Liquid Chromatography-Tandem Mass Spectrometry
}

\author{
Michael Vogeser ${ }^{1 *}$, Jan Groetzner ${ }^{2}$, Christina Küpper ${ }^{1}$ \\ and Josef Briegel $^{3}$ \\ ${ }^{1}$ Institute of Clinical Chemistry, \\ ${ }^{2}$ Clinic of Cardiac Surgery, \\ ${ }^{3}$ Clinic for Anesthesiology, \\ Hospital of the University of Munich-Grosshadern, Munich, \\ Germany
}

In severely ill patients low concentrations of the corticosteroid binding globulin are typically found; the aim of this study was to quantify directly free bioactive cortisol concentrations in the sera of postoperative cardiosurgical patients. Serum samples of 12 consecutive patients undergoing aortocoronary bypass surgery taken preoperatively and on the postoperative days 1 to 4 were analyzed. Total serum cortisol was quantified using liquid chromatography-tandem mass spectrometry with an on-line sample extraction system and tri-deuterated cortisol as the internal standard, and free serum cortisol was measured after over-night equilibrium dialysis. Whereas on the first postoperative day, the median total serum cortisol concentration was approximately two-fold increased compared to preoperative samples (preoperatively, $245 \mathrm{nmol} / \mathrm{I}$ (interquartile range (IQR) 203-293 nmol/I); first postoperative day, $512 \mathrm{nmol} / \mathrm{I}$ (IQR 410-611 nmol/I)), median dialyzable free cortisol concentration was almost seven-fold increased (preoperatively, $14.2 \mathrm{nmol} / \mathrm{I}$ (IOR 10.9-20.7 nmol/I); first postoperative day, $98.3 \mathrm{nmol} / \mathrm{I}$ (IQR 81.3-134 $\mathrm{nmol} / \mathrm{I})$ ). On the fourth postoperative day, median free cortisol was still significantly increased compared to baseline sampling ( $p<0.05$ ), whereas median total cortisol was not. A median of $5.7 \%$ (IQR 5.4-7.0\%) of total cortisol was found as free cortisol on the preoperative day, 21.2\% (IQR 18.9$23.5 \%$ ) on the first postoperative day and $10.5 \%$ (IQR 9.8-14.0\%) on the fourth postoperative day. It is concluded that during the postoperative period the freeto-bound ratio of cortisol is highly variable and that during the acute phase response direct quantification of free bioactive cortisol concentrations seems to be biologically more appropriate than the measurement of total cortisol concentrations. Clin Chem Lab Med 2003; 41(2):146-151

Key words: Cortisol; Equilibrium dialysis; Liquid chromatography-tandem mass spectrometry; Acute phase response.

*E-mail of the corresponding author:

Michael.Vogeser@klch.med.uni-muenchen.de
Abbreviations: $\mathrm{CBG}$, corticosteroid-binding globulin; $\mathrm{CRP}$, C-reactive protein; ED-LC-TMS, equilibrium dialysis liquid chromatography-tandem mass spectrometry; IQR, interquartile range.

\section{Introduction}

During acute phase response and in severe illness cortisol is of essential importance for immune modulation, maintenance of homeostasis and for cardiovascular regulation (1,2). Increased adrenal secretion of cortisol under the condition of severe stress - as during the postoperative period - has long been recognized (3, 4); additionally, recent investigations have demonstrated profound alterations in the transport of cortisol during acute phase response, which is characterized by a decline in the concentration of corticosteroid-binding globulin (CBG), potentially leading to very high free serum cortisol concentrations (5-11).

Previous studies addressing bioactive free cortisol concentrations in severely ill patients mainly relied on indirect calculations of free serum cortisol concentrations from the concentrations of total cortisol and CBG (10-13). These predictions, however, have not been validated by direct measurement of free serum cortisol in intensive care patients. The aim of this investigation was therefore to study systematically the concentrations of bioactive free cortisol in patients undergoing standardized major cardiac surgery - inducing extensive acute phase response and systemic inflammation - by use of a newly developed direct equilibrium dialysis liquid chromatography-tandem mass spectrometry (ED-LC-TMS) method and to compare these results with calculated free serum cortisol and total serum cortisol concentrations.

\section{Patients and Methods}

\section{Patients}

Twelve patients undergoing elective coronary artery bypass grafting with extracorporeal circulation were prospectively included into the investigation. Residual serum was used from samples that were taken for clinically indicated laboratory tests between 6.00 and 8.00 a.m. on the preoperative day and on the first 4 postoperative days. Samples were stored at $-20^{\circ} \mathrm{C}$ until analysis. Ten patients were male, two female, the age ranged from 54 to 81 years (median 68 years); anesthesia was induced with etomidate at doses of 14 to $20 \mathrm{mg}$. The study was approved by the Institutional Review Board. 


\section{Analytical methods}

Serum cortisol and cortisone were determined simultaneously as described previously $(14,15)$ using liquid chromatography-electrospray tandem mass spectrometry. In brief, samples and calibrators were precipitated with methanol/zinc sulfate containing tri-deuterated cortisol as the internal standard (Cambridge Isotope Laboratories, Andover, USA). After centrifugation, the supernatants were applied to on-line solidphase extraction with subsequent HPLC separation employing column switching (extraction column: Waters Oasis HLB (Waters, Milford, USA)), washed with $5 \%$ methanol, elution in back-flush with methanol/2 $\mathrm{mmol} / \mathrm{l}$ ammonium acetate $7 / 3$ by volume onto an analytical C18-HPLC column (Reprosil pur C18-AQ, $125 \times 2$ mm; 5 mm; Maisch, Ammerbuch, Germany). The HPLC system was coupled to a Micromass Quattro LC tandem mass spectrometer (Micromass, Manchester, UK) run in multiple reaction monitoring mode; the following transitions generated by collision induced disintegration of the respective $[\mathrm{M}+\mathrm{H}]$ ions were monitored: cortisol $363>309 \mathrm{~m} / \mathrm{z}$; d3-cortisol $366>312 \mathrm{~m} / \mathrm{z}$. All study samples were analyzed within two runs.

Equilibrium dialysis cells were prepared according to Reinard and Jacobsen (16) from commercially available $1.5 \mathrm{ml}$ polypropylene microtubes (Eppendorf, Germany; Figure 1). Lids of these tubes were cut off, placed upside down so that their recess functioned as a reservoir for approximately $240 \mu \mathrm{l}$ of a dialysis buffer (Nichols Dialysis Buffer). A dialysis membrane (regenerated cellulose, molecular weight cut-off 4000-6000 Da; Roth GmbH, Karlsruhe, Germany) was conditioned by first soaking in a large volume of $10 \mathrm{mmol} / \mathrm{l}$ sodium bicarbonate at $60^{\circ} \mathrm{C}$ for $1 \mathrm{~h}$ while stirring and subsequently by soaking in distilled water at the same temperature, again for $1 \mathrm{~h}$. After final washing in a large volume of distilled water, the membrane was cut into $1.5 \times 1.5 \mathrm{~cm}$ squares to be placed on the tube lids filled with the dialysis buffer. Tubes were then placed upside down on top of the lids, thereby fixing the diaIysis membranes. Finally the tips of the tubes were cut off to allow $1 \mathrm{ml}$ of serum to flow into the dialysis cells.

The cells were incubated for $16 \mathrm{~h}$ on a reciprocal shaker placed in a thermostated oven at $37^{\circ} \mathrm{C}\left( \pm 0.1^{\circ} \mathrm{C}\right)$. After incubation, the serum-containing tubes were removed and the dialysate was collected from the lids to be analyzed by liquid chromatography-tandem mass spectrometry in the same way as serum samples.

For quality control of total cortisol measurement commercially available materials were used (Lyphochek Immunoassay Plus, Biorad, Hercules, USA).

Serum CBG was quantified by a coated tube RIA (BioSource

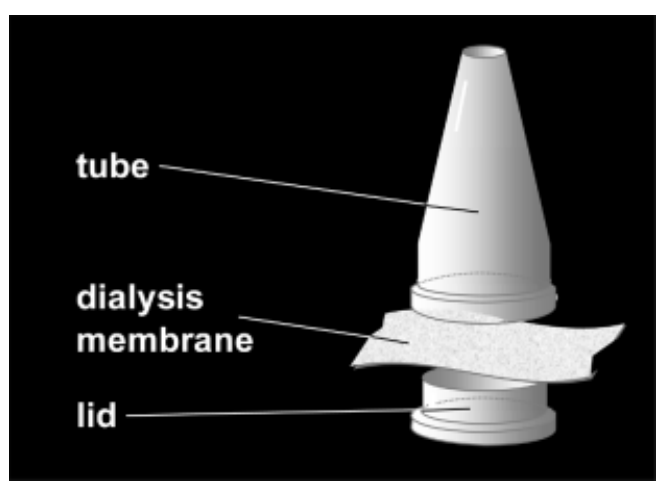

Figure 1 The assembly of the equilibrium dialysis cell for the determination of free cortisol by liquid chromatography-tandem mass spectrometry.
Europe, Nivelles, Belgium) in one single batch using kit control material for quality assurance. Serum albumin and C-reactive protein (CRP) were measured by routine automated turbidimetric immunoassays (Tina-quant ${ }^{\circledR}$, Roche Diagnostics, Mannheim, Germany).

To calculate serum free cortisol concentrations from total serum cortisol and CBG concentrations, the equation described by Coolens et al. (17) was applied:

Free serum cortisol $=\operatorname{SQR}\left(Z^{2}+0.0122 \times T\right)-Z$

with $Z=0.0167+0.0182 \times(C-T)$,

and C: CBG ( $\mu \mathrm{mol} / \mathrm{l})$; T: total cortisol $(\mu \mathrm{mol} / \mathrm{l})$; SQR:

square root

To study the imprecision of the ED-LC-TMS method for the determination of free serum cortisol, 12 aliquots of a normal serum pool were analyzed within three independent series to calculate the coefficient of variation.

\section{Statistical methods}

The $t$-test was used to test for statistically significant differences between results obtained in the preoperative and postoperative samples (day 1 to 4 ), with significance assumed for $\mathrm{p}<0.05$.

For method comparison between directly measured and calculated free serum, cortisol linear regression with Pearson's coefficient of correlation was calculated; additionally, a bias plot was generated according to Bland and Altman (18) with the calculation of the mean percentage difference between the methods.

\section{Results}

On the first postoperative day, median total serum cortisol concentration was approximately two-fold increased compared to the preoperative sampling (preoperatively, $245 \mathrm{nmol} / \mathrm{l}$ (interquartile range (IQR) 203-293 nmol/l); first postoperative day, $512 \mathrm{nmol} / \mathrm{l}$ (IQR 410-611 nmol/I), respectively). On subsequent days, median cortisol concentration declined, so that on the fourth postoperative day total serum cortisol was not significantly increased compared to the preoperative day (323 nmol/I (IOR 305-416 nmol/I)).

Median free cortisol concentration determined by ED-LC-TMS was almost seven-fold increased on the first postoperative day compared to baseline sampling (preoperatively, $14.2 \mathrm{nmol} / \mathrm{I}$ (IQR 10.9-20.7 nmol/I); first postoperative day, $98.3 \mathrm{nmol} / \mathrm{l}$ (IQR 81.3-134 nmol/I)). In contrast to total serum cortisol, free serum cortisol was still significantly increased on the fourth postoperative day (33.9 nmol/I (IOR 28.7-57.9 nmol/l; $p<0.05$ ) compared to the preoperative sampling.

The perioperative free-to-bound ratio of cortisol was highly variable with a median of $5.7 \%$ (IQR $5.4-7.0 \%$ ) of total cortisol found as free cortisol on the preoperative day, $21.2 \%$ (IOR $18.9-23.5 \%$ ) on the first postoperative day and $10.5 \%$ (IQR $9.8-14.0 \%$ ) on the fourth postoperative day $(p<0.05)$.

The median concentration of CBG found on the first postoperative day was $53 \%$ of the median concentration found preoperatively; the median concentration remained significantly decreased until the fourth post- 
Table 1 Perioperative concentrations of total serum cortisol and free serum cortisol determined by equilibrium dialysis liquid chromatography-tandem mass spectrometry (ED-LCTMS), calculated free serum cortisol, corticosteroid-binding globulin (CBG), albumin, C-reacitve protein (CRP), and the percentage of free cortisol of total cortisol in 12 patients undergoing coronary bypass surgery ${ }^{1}$.

\begin{tabular}{|c|c|c|c|c|c|c|}
\hline & & -1 & POD 1 & POD 2 & POD 3 & POD 4 \\
\hline Total cortisol & $\mathrm{nmol} / \mathrm{l}$ & $\begin{array}{l}245.0 \\
(203-293)\end{array}$ & $\begin{array}{l}512.0 * \\
(410-611)\end{array}$ & $\begin{array}{l}454.0 * \\
(348-517)\end{array}$ & $\begin{array}{l}386.0 * \\
(322-458)\end{array}$ & $\begin{array}{l}323.0 \\
(305-416)\end{array}$ \\
\hline $\begin{array}{l}\text { Free cortisol by } \\
\text { ED-LC-TMS }\end{array}$ & $\mathrm{nmol} / \mathrm{l}$ & $\begin{array}{l}14.2 \\
(10.9-20.7)\end{array}$ & $\begin{array}{l}98.3^{*} \\
(81.3-134.5)\end{array}$ & $\begin{array}{l}78.7 * \\
(46.1-101.4)\end{array}$ & $\begin{array}{l}68.2^{*} \\
(38.5-74.3)\end{array}$ & $\begin{array}{l}33.9 * \\
(28.7-57.9)\end{array}$ \\
\hline$\%$ free cortisol & $\%$ & $\begin{array}{l}5.7 \\
(5.4-7.0)\end{array}$ & $\begin{array}{l}21.2^{*} \\
(18.9-23.5)\end{array}$ & $\begin{array}{l}16.0^{*} \\
(12.8-19.9)^{*}\end{array}$ & $\begin{array}{l}15.4^{*} \\
(12.8-16.9)\end{array}$ & $\begin{array}{l}10.5^{*} \\
(9.8-14.0)\end{array}$ \\
\hline $\begin{array}{l}\text { Calculated free } \\
\text { cortisol }\end{array}$ & $\mathrm{nmol} / \mathrm{l}$ & $\begin{array}{l}14.1 \\
(11.2-21.6)\end{array}$ & $\begin{array}{l}78.4^{*} \\
(62.3-113)\end{array}$ & $\begin{array}{l}55.2^{*} \\
(43.9-79.2)\end{array}$ & $\begin{array}{l}44.2^{*} \\
(33.8-63.9)\end{array}$ & $\begin{array}{l}31.1^{*} \\
(26.0-45.5)\end{array}$ \\
\hline CBG & $\mathrm{nmol} / \mathrm{l}$ & $\begin{array}{l}736.0 \\
(587-800)\end{array}$ & $\begin{array}{l}392.0 * \\
(366-431)\end{array}$ & $\begin{array}{l}425.0 * \\
(368-463)\end{array}$ & $\begin{array}{l}478.0 * \\
(406-518)\end{array}$ & $\begin{array}{l}503.0 * \\
(466-532)\end{array}$ \\
\hline Albumin & $g / l$ & $\begin{array}{l}48.0 \\
(47-49)\end{array}$ & $\begin{array}{l}27.0^{*} \\
(24-29)\end{array}$ & $\begin{array}{l}28.0 * \\
(23-30)\end{array}$ & $\begin{array}{l}26.0 * \\
(25-30)\end{array}$ & $\begin{array}{l}28.0 * \\
(27-30)\end{array}$ \\
\hline CRP & $\mathrm{mg} / \mathrm{l}$ & $\begin{array}{l}<5 \\
(<5-<5)\end{array}$ & $\begin{array}{l}67.0 * \\
(59-92)\end{array}$ & $\begin{array}{l}189.0 * \\
(153-233)\end{array}$ & $\begin{array}{l}167.0 * \\
(142-194)\end{array}$ & $\begin{array}{l}116.0^{*} \\
(80-120)\end{array}$ \\
\hline
\end{tabular}

${ }^{1}$ Median and interquartile ranges; POD, postoperative day; ${ }^{*}$ denotes statistically significant differences of the respective parameter with regard to the preoperative day.

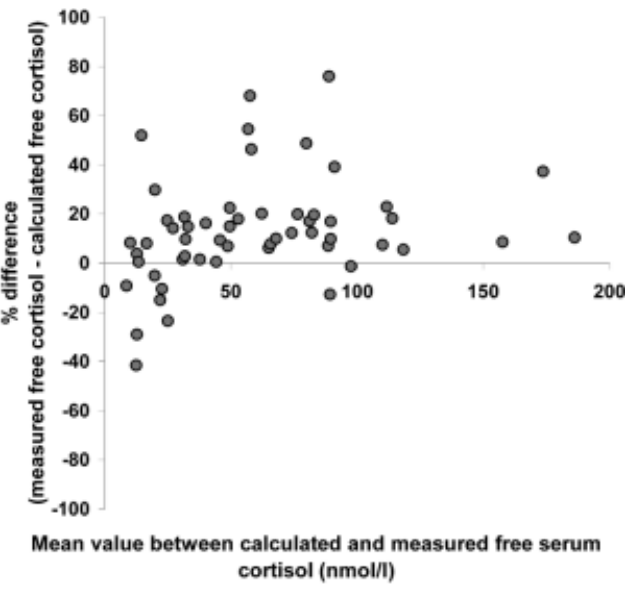

Figure 2 Bias plot according to Bland and Altman (18) of free serum cortisol concentrations determined directly by equilibrium dialysis liquid chromatography-tandem mass spectrometry and calculated from the concentrations of total serum cortisol and corticosteroid-binding globulin.

operative day reaching $68 \%$ of the preoperative concentration at the end of the observation period. Median serum albumin concentrations were also significantly lower on all postoperative days compared to the preoperative concentrations. The median CRP concentration peaked on the second postoperative day with $190 \mathrm{mg} / \mathrm{l}$ (IOR 154-233 mg/l). The raw data of the respective analyses are given in Table 1.

Comparison of free serum cortisol concentrations both measured directly by ED-LC-TMS and calculated according to Coolens et al. (17) by regression analysis resulted in the following equation: [calculated free cortisol $]=[$ free cortisol by ED-LC-TMS] $\times 0.78+4.1 \mathrm{nmol} / \mathrm{l}$

with a Pearson's coefficient of correlation 0.95.

The method comparison according to Bland and Altman (18) demonstrated a mean percentage difference between the two methods ([free cortisol by ED-LCTMS] - [calculated free cortisol]) of $13.2 \%$ (standard deviation $21.2 \%$ ) with the differences ranging from $-41.5 \%$ to $+75 \%$; the respective bias plot is given in Figure 2.

An interassay coefficient of variation of $8.1 \%$ was observed for the free serum cortisol measurement by ED-LC-TMS(mean concentration $12.1 \mathrm{nmol} / \mathrm{l}, \mathrm{n}=12$ in three series).

\section{Discussion}

In this investigation, free bioactive serum cortisol concentrations were measured directly by use of ED-LCTMS in sera of postoperative cardiac intensive care patients; it was found that free cortisol concentrations demonstrated a substantially more pronounced dynamics during the postoperative acute phase response compared to total cortisol. Whereas the median total cortisol concentration was increased about two-fold on the first postoperative day compared to the preoperative day, median free bioactive cortisol increased nearly seven-fold. At the end of the investigation period median free serum cortisol was still significantly increased compared to the preoperative sampling (139\% above baseline), whereas at this time point median total cortisol concentration was only slightly and 
not significantly higher than the median preoperative concentration ( $31 \%$ above baseline). These results correspond to a substantial increase in the ratio of free-tototal cortisol from $5.7 \%$ preoperatively to as much as $21.2 \%$ on the first postoperative day.

Since in general only the free hormone fraction is considered to be biologically active $(19,20)$, our data suggest that during the acute phase response free serum cortisol measurement is biologically more appropriate compared to the measurement of total cortisol. We decided to study cortisol protein binding during acute phase response in patients undergoing elective cardiac bypass surgery with extracorporeal circulation because this well standardized procedure induces extensive stress and systemic inflammatory response (as demonstrated by very high CRP concentrations), and individual baseline samples can be taken in a non-stressed state before the patient is transferred to intensive care; this is not the case, for example, in a heterogeneous population of intensive care patients with septic shock.

The observation of very high free serum cortisol concentrations and an increased free-to-bound ratio of cortisol in the postoperative period after cardiac surgery is qualitatively in accordance with previous investigations, where calculations were applied to estimate free cortisol concentrations $(10,11)$. Except for one study on burn patients (9), studies addressing bioactive cortisol in severely ill patients have so far relied on calculations based on the concentrations of total serum cortisol and CBG, respectively (10-13); these calculations, however, have not been so far validated by comparison with directly measured free serum cortisol in intensive care patients.

The simplest approach to estimate free serum cortisol is the calculation of a [cortisol]/[CBG] ratio as a "free cortisol index" $(13,21)$. The algorithm described by Coolens et al. (17) applied in other studies $(10,12)$ takes into account the binding characteristics of CBG and is applicable by use of standard spreadsheet software; this calculation, however, is simplified in that the concentration of albumin and sexhormone-binding globulin (as other important cortisol-binding proteins), and competing steroids as cortisone are not incorporated. Conclusive calculation of free serum cortisol concentrations taking into account the latter variables, however, is not generally applicable, since it leads to complex equations which have to be solved by numeric procedures for which no software is commercially available $(11,19,22)$. Interestingly, calculations that incorporate the binding characteristics of CBG and cortisol - both in a simplified form (17) and by computer simulation (22) predict a non-linear rise in bioactive free serum cortisol with increasing total serum cortisol concentrations, even at constant CBG concentrations and within the physiological range of circadian variation of cortisol concentrations; a simple "free cortisol index" $(13,21)$ fails to display this and should not be used.

By linear regression analysis we found an apparently close correlation between free serum cortisol concentrations calculated according to Coolens et al. (17) and free cortisol measured directly by ED-LC-TMS, with a coefficient of correlation of 0.95 . Bias analysis according to Bland and Altman (18), however, demonstrated poor commutability of the results for individual samples, an important mean percentage difference of $13.2 \%$, and individual differences of up to $75 \%$ between both methods of free cortisol determination. This relevant bias between calculated and measured free cortisol concentrations observed in samples of intensive care patients may arise from changes in the binding properties of CBG known to occur in acute phase response $(6,23)$ or from compounds that interfere with cortisol protein binding, such as free fatty acids (24).

The technique of ED-LC-TMS developed for our study proved precise, convenient and applicable to large studies. Free hormone determination after equilibrium dialysis without dilution may be regarded as the highest attainable standard for this purpose (20). In the less laborious (but more expensive) technique of ultracentrifugation $(17,25)$, protein concentration on the filtration membranes with local volume compression effects can affect hormone binding. Dialysis with dilution by a large volume of dialysis buffer can potentially alter the physiological free-to-bound equilibrium since the distribution volume of cortisol is largely increased, whereas the sample volume remains unchanged. For the quantification of cortisol in the obtained dialysate or filtrate, conventional HPLC techniques or immunoassays, as applied so far $(25,26)$, lack sensitivity (with detection limits typically above $10 \mathrm{nmol} / \mathrm{l}$ ) and specificity (with respect to cortisone and cortisol conjugate metabolites), whereas tandem mass spectrometry as applied in our investigation proved highly precise and specific (14).

CBG is a $52 \mathrm{kDa}$ glycoprotein that exhibits structural homology to serine protease inhibitors (27-30). Low concentrations of CBG found after major surgery may be explained by several mechanisms: (i) the negative acute phase behavior of CBG with decreased synthesis in response to inflammatory mediators (31-33), (ii) the conformational changes and active depletion of CBG $(8,23,30)$, and (iii) the in vivo serum dilution following substantial blood loss and fluid replacement. This latter dilution effect was suggested in our and and in a previous investigation (11) by the markedly decreased concentrations of serum albumin during the postoperative period.

Besides alterations in cortisol binding, other changes in the hypothalamic-pituitary-adrenal axis in severe illness have been recognized, such as an increased adrenal sensivity towards ACTH $(4,34,35)$, a continuous rather than pulsatile pattern of cortisol section (3), and changes in the number and sensitivity of glucocorticoid receptors $(36,37)$. Recently we were able to demonstrate substantial changes in the peripheral metabolism of cortisol during acute phase response (38) with a significant shift of the systemic set-point from inactive cortisone towards active cortisol. This shift can be explained by increased activity of $11 \beta$-hydroxysteroid dehydrogenase type I that is mainly expressed in liver tissue regenerating inactive cortisone to active cortisol $(39,40)$. The latter mechanism, as well as the out-of-pro- 
portion increase in bioactive free cortisol observed in the present study lead to enhanced bioavailability of cortisol in addition to a mere increase in adrenal cortisol synthesis during acute phase response.

Despite these general mechanisms to increase active cortisol concentrations in acute phase response, it has been recognized that in patients with septic shock relative glucocorticoid deficiency arises frequently (1, 41). This relative adrenal failure can be verified by stimulation testing with exogenous $\mathrm{ACTH}$; respective cutoff values have been demonstrated to be of prognostic significance (42) and are used to guide low-dose cortisol substitution $(1,41)$. It is evident from this background that cortisol measurement will gain importance in intensive care medicine. Since the alterations of CBG and albumin concentrations are variable among severely ill patients and the dynamics of free serum cortisol is quite different from that of total serum cortisol in critically ill patients, as shown in the present investigation, cut-off values for therapeutic decisions in intensive care medicine might be based on the measurement of free bioactive cortisol rather than on total cortisol. Therefore, the development of immunoassays for quantification of free serum cortisol in a routine clinical setting - by analogy to the measurement of free thyroid hormones - seems reasonable; the technique of ED-LC-TMS developed for our study may serve as a candidate reference method for this purpose.

\section{References}

1. Lamberts SW, Bruining HA, de Jong FH. Corticosteroid therapy in severe illness. N Engl J Med 1997; 337:1285-92.

2. Briegel J, Kilger E, Schelling G. Stress doses of hydrocortisone in septic shock: Beyond the hemodynemic effects. In: Vincent, J-L, editor. 1999 Yearbook of intensive care and emergency medicine. Berlin; Heidelberg; New York: Springer, 1999:189-98.

3. Udelsman R, Norton JA, Jelenich SE, Goldstein DS, Linehan WM, Loriaux DL, et al. Responses of the hypothalamic-pituitary-adrenal and renin-angiotensin axes and the sympathetic system during controlled surgical and anesthetic stress. J Clin Endocrinol Metab 1987; 64:986-94.

4. Harris MJ, Baker RT, McRoberts JW, Mohler JL. The adrenal response to trauma, operation and cosyntropin stimulation Surg Gynecol Obstet 1990; 170:513-6.

5. Savu L, Zouaghi H, Carli A, NunezEA. Serum depletion of corticosteroid-binding activities, an early marker of human septic shock. Biochem Biophys Res Commun 1981; 102:411-9.

6. Pugeat M, Bonneton A, Perrot D, Rocle-Nicolas B, Lejeune $\mathrm{H}$, Grenot $\mathrm{C}$, et al. Decreased immunoreactivity and binding activity of corticosteroid-binding globulin in serum in septic shock. Clin Chem 1989; 35:1675-9.

7. Tinnikov AA, Legan MV, Pavlova IP, Litasova EE, Ivanova LN. Serum corticosteroid-binding globulin levels in children undergoing heart surgery. Steroids 1993; 58:536-9.

8. Garrel DR. Corticosteroid-binding globulin during inflammation and burn injury: nutritional modulation and clinical implication. Horm Res 1996; 45:245-51.

9. Bernier J, Jobin N, Emptoz-Bonneton A. Decreased corticosteroid-binding globulin in burn patients: relationship with interleukin- 6 and fat in nutritional support. Crit Care Med 1998; 26:452-60.
10. Vogeser M, Felbinger TW, Kilger E, Röll W, Fraunberger $P$, Jacob K. Corticosteroid-binding globulin and free cortisol in the early postoperative period after cardiac surgery. Clin Biochem 1999; 32:213-6.

11. Roth-Isigkeit AK, Dibbelt L, Schmucker P. Blood levels of corticosteroid-binding globulin, total cortisol and unbound cortisol in patients undergoing coronary artery bypass grafting surgery with cardiopulmonary bypass. Steroids 2000; 65:513-20.

12. Oppert M, Reinicke A, Graef KJ, Barckow D, Frei U, Eckardt K-U. Plasma cortisol levels before and during "low-dose" hydrocortisone therapy and their relationship to hemodynamic improvement in patients with septic shock. Intensive Care Med 2000; 26:1747-55.

13. Beishuizen A, Thijs LG, Vermes I. Patterns of corticosteroid-binding globulin and the free cortisol index during septic shock and multitrauma. Intensive Care Med 2001; 27:1584-91.

14. Vogeser M, Briegel J, Jacob K. Determination of serum cortisol by isotope-dilution liquid-chromatography electrospray ionization tandem mass spectrometry with online extraction. Clin Chem Lab Med 2001; 39:944-7.

15. Vogeser M, Zachoval R, Jacob K. Serum cortisol/cortisone ratio after Synacthen stimulation. Clin Biochem 2001; 34:421-5.

16. Reinard T, Jacobsen HJ. An inexpensive small volume equilibrium dialysis system for protein-ligand binding assays. Anal Biochem 1989; 176:157-60.

17. Coolens JL, Van Baelen H, Heyns W. Clinical use of unbound plasma cortisol as calculated from total cortisol and corticosteroid-binding globulin. J Steroid Biochem 1987; 26:197-202.

18. Bland JM, Altman DG. Statistical methods for assessing agreement between two methods of clinical measurement. Lancet 1986; i:307-10.

19. Brien TG. Pathophysiology of free cortisol in plasma. Ann New York Acad Sci 1988; 538:130-6.

20. Ekins R. Measurement of free hormones in blood. Endocrine Reviews 1990; 11:5-46.

21. Bonte $H A$, van den Hoven $R$, van der Sluijs Veer $G$, Vermes I. The use of free cortisol index for laboratory assessment of pituitary-adrenal function. Clin Chem Lab Med 1999; 37:127-32.

22. Dunn JF, Nisula BC, Rodbard D. Transport of steroid hormones: binding of 21 endogenous steroids to both testosterone-binding globulin and corticosteroid-binding globulin in human plasma. J Clin Endocinol Metb 1981; 53:5868.

23. Pemberton PA, Stein PE, Pepys MB, Potter JM, Carrell RW. Hormone binding globulins undergo serpin conformational change in inflammation. Nature 1988; 336:257-8.

24. Haourigui M, Sakr S, Martin ME, Thobie N, Girard-Globa A, Benassayag C, Nunez EA. Postprandial free fatty acids stimulate activity of human corticosteroid binding globulin. Am J Physiol 1995; 269:E1067-75.

25. Lentjes EGWM, Romijn F, Maassen RJ, de Graaf L, Gautier $P$, Moolenaar AJ. Free cortisol in serum assayed by temperature-controlled ultrafiltration before fluorescence polarization immunoassay. Clin Chem 1993; 39:2518-21.

26. Clerico A, Del Chicca MG, Ferdeghini M, Ghione S, Materazzi F. Progressively elevated levels of biologically active (free) cortisol during pregnancy by a direct radioimmunological assay of diffusible cortisol in an equilibrium dialysis system. J Endocrinol Invest 1980; 3:185-7.

27. Hammond GL, Smith CL, Goping IS, Underhill DA, Harley $\mathrm{MJ}$, Reventos J, et al. Primary sturcture of human corticosteroid binding globulin, deduced from hepatic and pul- 
monary cDNAs, exhibits homology with serine protease inhibitors. Proc Natl Acad Sci USA 1987; 84:5153-7.

28. Heyns W, Coolens JL. Physiology of corticosteroid-binding globulin in humans. Ann New York Acad Sci 1988; 538:122-9.

29. Hammond GL, Smith CL, Underhill DA. Molecular studies of corticosteroid binding globulin structure, biosynthesis and function. J Steroid Biochem Mol Biol 1991; 40:755-62.

30. Rosner W. Plasma steroid-binding globulins. Endocrinol Metab Clin North Am 1991; 20:697-720.

31. Bartalena L, Hommond GL, Farsetti A, Flink IL, Robbins J. Interleukin-6 inhibits corticosteroid-binding globulin synthesis by human hepatoblastoma-derived (Hep G2) cells. Endocrinology 1993; 133:291-6.

32. Emptoz-Bonneton A, Crave JC, LeJeune H, Brebant C, Pugeat $\mathrm{M}$. Corticosteroid-binding globulin synthesis regulation by cytokines and glucocorticoids in human hepatoblastoma-derived (HepG2) cells. J Clin Endocrinol Metab 1997; 82:3758-62.

33. Tsigos C, Kyrou I, Chrousos GP, Papanicolaou DA. Prolonged suppression of corticosteroid-binding globulin by recombinant human interleukin-6 in man. J Clin Endocrinol Metab 1998; 83:3379-82.

34. Jurney TH, Cockrell JL, Lindberg JS, Lamiell JM, Wade CE. Spectrum of serum cortisol response to ACTH in ICU patients. Chest 1987; 92:292-5.

35. Reincke M, Allolio B, Wurth G, Winkelmann W. The hypothalamic-pituitary-adrenal axis in critical illness: response to dexamethasone and corticotropin-releasing hormone. J Clin Endocrinol Metab 1993; 77:151-6.

36. Zonghai H, Han G, Renbao X. Study on glucocorticoid receptors during intestinal ischemia shock and septic shock. Circ Res 1987; 23:27-36.
37. Sun X, Fischer DR, Pritts TA, Wray CJ, Hasselgren PO. Expression and binding activity of the glucocorticoid receptor are upregulated in septic muscle. Am J Physiol Regul Integr Comp Physiol 2002; 282:R509-18.

38. Vogeser M, Zachoval R, Felbinger TW, Jacob K. Increased ratio of serum cortisol to cortisone in acute phase response. Horm Res 2002; 58:172-5.

39. Edwards CR, Benediktsson R, Lindsay RS, SeckI JR. 11 beta-Hydroxysteroid dehydrogenases: key enzymes in determining tissue-specific glucocorticoid effects. Steroids 1996; 61:263-9.

40. Krozowski Z, Li KX, Koyama K, Smith RE, Obeyesekere VR, Stein-Oakley A, et al. The type I and type II 11 beta-hyroxysteroid dehydrogenase enzymes. J Steroid Biochem Mol Biol 1999; 69:391-401.

41. Briegel J, Forst H, Haller M, Schelling G, Kilger E, Kuprat G, et al. Stress doses of hydrocortisone reverse hyperdynamic septic shock: a prospective, randomized, doubleblind, single-center study. Crit Care Med 1999; 27:723-32.

42. Annane D, Sebille V, Troche G, Raphael JC, Gajdos P, Bellissant $E$. A 3-level prognostic classification in septic shock based on cortisol levels and cortisol response to corticotropin. J Am Med Assoc 2000; 283:1038-45.

Received 31 July 2002, revised 12 November 2002, accepted 21 November 2002

Corresponding author: Dr. med. Michael Vogeser, Institut für Klinische Chemie, Klinikum der Universität MünchenGroßhadern, 81366 Munich, Germany

Phone: 004989 / 7095 3246, Fax: 004989 / 7095 3240, E-mail: Michael.Vogeser@klch.med.uni-muenchen.de 